\title{
Pengaruh Penambahan Free dan Fix Drag Reducing Pada Bilah terhadap Kinerja Turbin Angin Savonius
}

\section{Effects of Addition of Free and Fix Drag Reducing On Blades to the Performance of Savonius Wind Turbine}

\author{
Indra Herlamba Siregar ${ }^{1, *}$, Moch Effendy ${ }^{2}$ dan Akhmad Hafizh Ainur Rasyid ${ }^{3}$ \\ 1,2,3 Jurusan Teknik Mesin, Fakultas Teknik, Universitas Negeri Surabaya \\ ${ }^{1}$ indrasiregar@unesa.ac.id \\ ${ }^{2}$ m_effendy2001@yahoo.com \\ 3akhmadrasyid@unesa.ac.id
}

\begin{abstract}
Abstrak - Indonesia dengan karekteristik angin yang sering berubah-ubah arah serta kecepatannya tergolong rendah, memerlukan sebuah desain turbin angin yang sesuai. Turbin angin Savonius adalah jenis turbin yang sesuai dengan karekteristik angin di Indonesia. Pada penelitian sekarang bilah turbin angin Savonius di tambahi peralatan yang berfungsi untuk mengurangi drag terutama pada returning blade, peralatan ini ada yang bergerak bebas disebut free drag reducing dan ada pula dengan sudut tertentu disebut fix drag reducing. Hasil penelitian memaparkan bahwa penambahan peralatan yang bergerak bebas pada bilah menghasilkan kinerja turbin angin yang lebih baik daripada penambahan peralatan dengan sudut tertentu pada bilah.
\end{abstract}

Kata Kunci- Karekteristik angin, savonius, returning blade, free drag reducing, fix drag reducing.

\begin{abstract}
Indonesia with wind characteristics that often change direction and speed is relatively low, requiring an appropriate wind turbine design. Savonius wind turbines are a type of turbine that is in accordance with wind characteristics in Indonesia. In the present study Savonius wind turbine blades are added with equipment that serves to reduce drag, especially on returning blades, these devices are free moving called free drag reducing and some with certain angles called drag reducing fixes. The results of the study explained that the addition of free moving equipment on the blades produced a better performance of the wind turbine than the addition of equipment with a certain angle on the blade.
\end{abstract}

Key Words - Wind characteristics, savonius, returning blade, free drag reducing, fix drag reducing.

\section{Pendahuluan}

Turbin angin Savonius adalah turbin angin sumbu vertikal yang pertama kali dibuat oleh insinyur Finlandia Sigurd Savonius di 1925. Turbin ini digerakkan oleh gayar drag, bahkan jika, untuk beberapa posisi sudut rotor, untuk kondisi tertentu ada kontribusi gaya lift pada mekanisme terciptanya torsi, sebagaimana dibuktikan oleh nilai-nilai rasio kecepatan tip (1) lebih besar dari satu [1].

Turbin angin Savonius memiliki kelebihan antara lain konstruksi sederhana, hemat biaya, dan andal. Selain itu, rotor angin Savonius tidak perlu diorientasikan ke arah angin, dan memiliki nilai torsi yang tinggi. Namun turbin jenis ini memiliki kelemahan, jika dibandingkan dengan turbin angin lainnya yaitu kinerjanya yang lebih rendah; untuk alasan ini, yang terakhir empat dekade beberapa penulis telah mencoba mengembangkan solusi yang berbeda, dengan target umum untuk menyelesaikan kelemahan utamanya [2]. Solusi semacam itu sebagian besar mengandalkan modifikasi sejumlah parameter geometri yang mempengaruhi kinerja turbin angin savonius: di antaranya, jumlah bilah, jarak dan tumpang tindih relatifnya, jumlah tingkat dan pergeseran sudutnya, sudut putar turbin angin savonius dan aspek rasio. Selain itu, penggunaan pelengkap aerodinamis bisa berguna untuk meningkatkan kinerja global turbin angin savonius.

Namun demikian, bidang penelitian yang lebih menantang menyangkut peningkatan kinerja aerodinamis Savonius turbin angin savonius angin melalui pengembangan bentuk pisau baru seperti yang dilakukan oleh Modi dan Fernando [1] mengusulkan bilah geometri baru yang terbukti mampu meningkatkan koefisien daya maksimum turbin angin savonius (Cp, maks). Rahai et al. [3] mewujudkan optimasi aerodinamis proses turbin angin savonius berbentuk airfoil yang sebelumnya diusulkan oleh Benesh [4], mendapatkan peningkatan yang terkait dengan karekteristik dinamis. Kamoji et al. [5] mengusulkan versi yang sedikit dimodifikasi dari turbin angin savonius Savonius yang sebelumnya dikembangkan oleh Modi dan Fernando [1], mendapatkan peningkatan dalam hal kinerja statis dan dinamis.

Mohamed et al. [6], dengan menggunakan algoritma evolusioner, bentuk bilah turbin angin savonius dioptimalkan dengan adanya pelat datar yang melindungi returning blade, dimana keberadaan returning blade mampu meningkatkan kinerja turbin angin savonius. Kacprzak et al. [7] melakukan analisis numeric bilah turbin angin Savonius konvensional dan modifikasi, hasil penelitian memaarkan bahwa penggunaan geometri bilah yang berbeda dari bentuk semi-silinder standar adalah salah satu cara untuk meningkatkan kinerja energi turbin angin Savonius.

Siregar dkk. [8], menambahkan fix drag reducing dengan berbagai bukaan sudut pada bilah. Hasil penelitian memaparkan bahwa bukaan sudut $15^{\circ}$ dari fix drag reducing mampu meningkatkan kinerja turbin angin savonius daripada turbin angin tanpa fix drag reducing. 
Wahid dkk. [9], menambahkan peralatan yang berfungsi sebagai drag reducing yang bergerak bebas atau dinamakan free drag reducing. Hasil penelitian memaparkan bahwa penambahan peratalatan free drag reducing mampu meningkatkan kinerja turbin angin savonius.

Pada penelitian sekarang, peneliti ingin membandingkan penambahkan peralatan yang berfungsi sebagai pengurang drag pada bilah yaitu free drag reducing dan fix drag reducing terhadap kinerja turbin angin savonius.

\section{Metoda Penelitian}

Pada penelitian yang dilakukan sekarang adalah pengujian model turbin angin di terowongan angin subsonic dengan luas penampang keluar $2025 \mathrm{~cm}^{2}$ dengan inverter kecepatan.

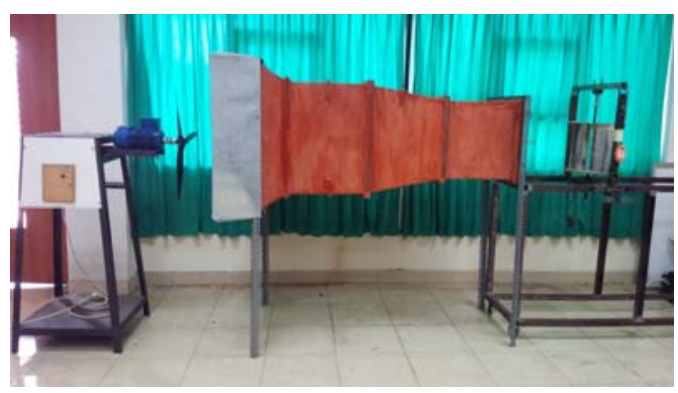

Gambar 1. Instrumen dan Peralatan Uji

Adapun spesifikasi model dapat dilihat pada table 1 dengan gambar sket diperlihatkan pada gambar 2 .

\begin{tabular}{ll} 
Tabel 1. Spesifikasi model uji turbin angin \\
\hline Parameter & Bentuk/Nilai \\
\hline Profile Bilah & $\mathrm{C}$ \\
Jumlah & 2 \\
Panjang busur, [cm] & 14 \\
Diameter Rotor, [cm] & 30 \\
Diameter Poros, [cm] & 1,5 \\
Jumlah FDR & 3 per bilah \\
Dimensi [cm $\left.{ }^{2}\right]$ & $5 \times 5$ \\
Bahan disk atas & Arcliryc \\
Bahan disk bawah & Arcliryc \\
Bahan bilah & Plat seng \\
\hline
\end{tabular}

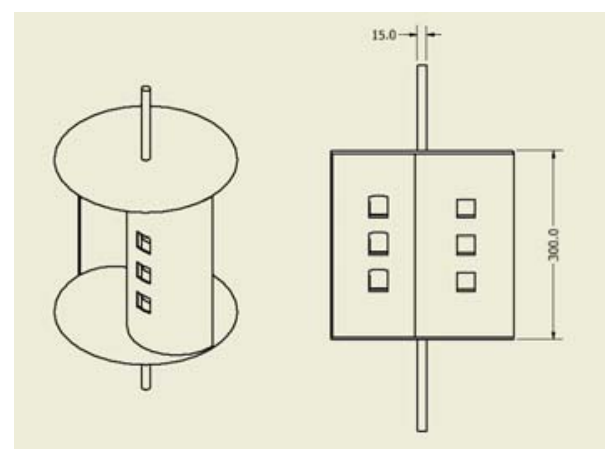

Gambar 2. Model Turbin Angin yang diteliti

Untuk parameter uji adalah besar dari bukaan fix drag reducing yang dipasang pada bilah dengan bukaan sudut sebesar $15^{\circ}$ yang menghasilkan kinerja ang terbaik dari hasil penelitian siregar dkk [8] dengan free drag reducing pada kecepatan angin 3 sampai $6 \mathrm{~m} / \mathrm{s}$ sesuai dengan kondisi kecepatan angin rata-rata di Indonesia

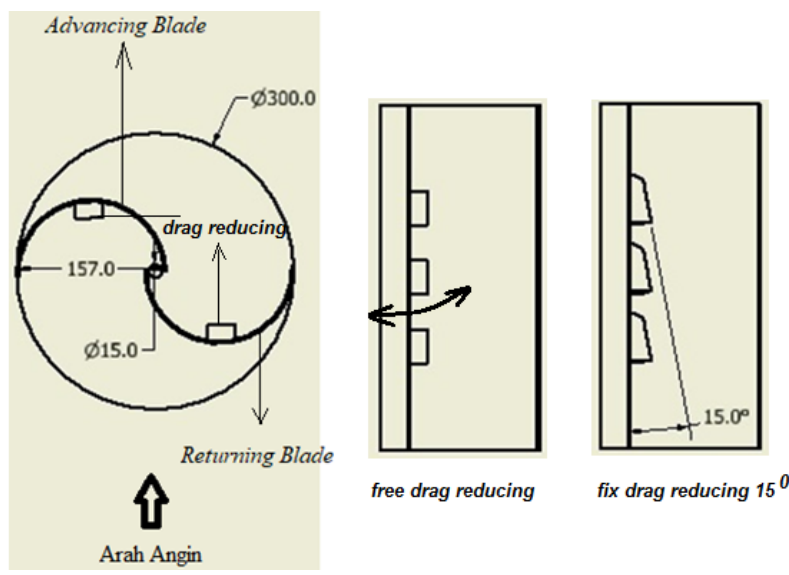

Gambar 3. Bilah dengan free da fix drag reducing

\section{HASIL DAN PEMBAHASAN}

Perbandingan parameter kinerja dari model turbin angin sumbu vertikal dengan free dan fix drag reducing pada bilah turbin angin Savonius di paparkan dalam bentuk grafik power density dan Koefisien kinerja model uji turbin angin $(\mathrm{Cp})$ dengan berbagai variasi kecepatan angin dapat dilihat pada gambar 4 dan 5 .



Gambar 4. Variasi Power density terhadap kecepatan angin

Dari gambar 4 terlihat bahwa penambahan free drag reducing pada bilah turbin angin Savonius berdampak signifikan pada peningkatan daya yang dihasilkan oleh turbin angin Savonius dibandingkan dengan penambahan fix drag reducing pada bilah. Gambar 4 juga memaparkan bahwa semakin tinggi kecepatan angin maka peningkatannya pun 
semakin besar, hal ini diduga dengan posisi engsel yang bebas maka aliran yang menerpa bilah advancing blade akan tertutup sehingga drag yang timbul lebih besar daripada bilah yang di berikan fix drag reducing dengan sudut $15^{\circ}$ yang memberikan celah sedikit sehingga ada bagian udara yang keluar sehingga drag yang di timbulkan lebih kecil. Begitupula sebaliknya penambahan free drag reducing pada bagian returning blade dikarenakan enselnya bebas maka ketika aliran menerpa returning blade free drag reducing juga membuka sehingga drag yang dihasilkan pada bilah sisi ini akan lebih kecil.

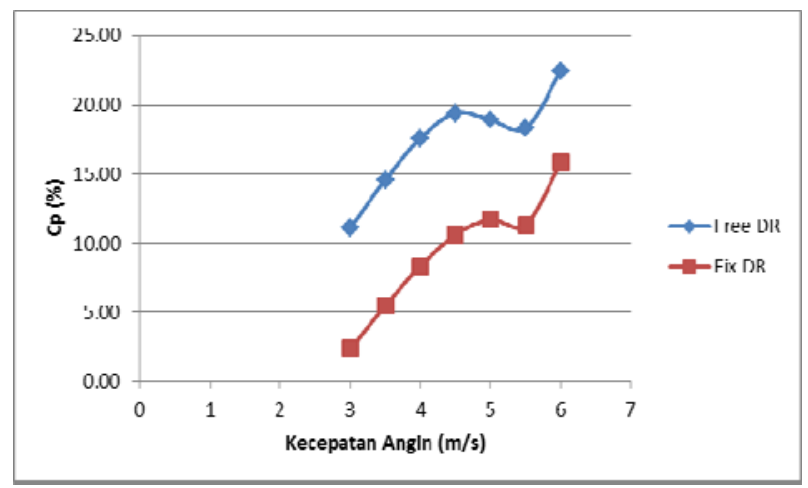

Gambar 5. Variasi Cp terhadap kecepatan angin

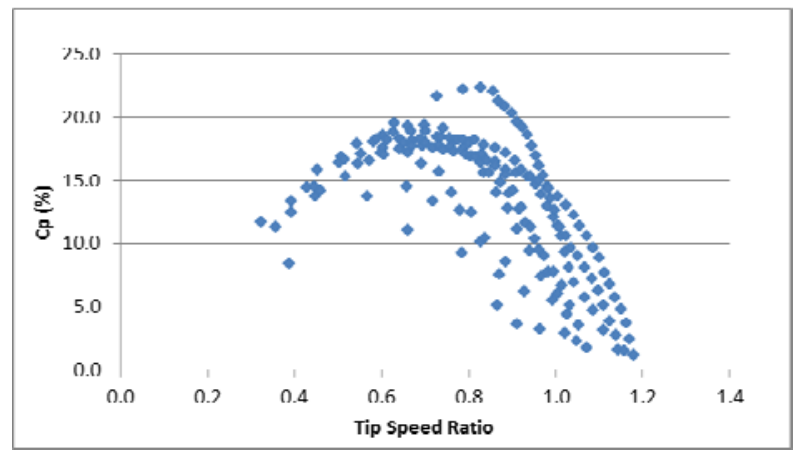

Gambar 6. Variasi Cp terhadap tip speed rasio untuk bilah dengan free drag reducing

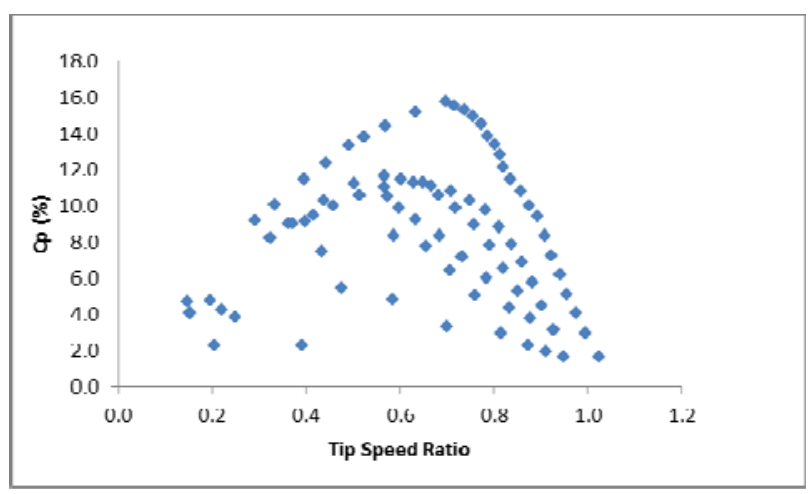

Gambar 7. Variasi Cp terhadap tip speed rasio untuk bilah dengan fix drag reducing

Distribusi coefficient of performance $(\mathrm{Cp})$ terhadap tip speed rasio $(\lambda)$ dipaparkan pada gambar 6 dan 7. Dari gambar 6 dan terlihat bahwa penambahan free drag reducing pada bilah juga menimbulkan gaya lift hal ini ditandai dengan nilai tip speed ratio lebih besar dari satu [1]. Adanya gaya lift inilah yang diduga sebagai penyebab nilai $\mathrm{Cp}$ dan daya yang dihasilkan oleh turbin angin savonius dengan penambahan free drag reducing pada bilah lebih besar daripada bilah dengan penambahan fix drag reducing karena gaya yang terjadi merupakan resultan dari gaya drag dan gaya lift.

Dari gambar 6 terlihat bahwa efisiensi maksimum yang dihasilkan bilah dengan penambahan free drag reducing mencapai $23 \%$ pada tip speed rasio 0,8 yang terjadi pada kecepatan angin $6 \mathrm{~m} / \mathrm{s}$ lihat gambar 5 . Sedangkan efisiensi maksimum yang dihasilkan bilah dengan penambahan fix drag reducing mencapai $16 \%$ pada tip speed rasio 0,7 lihat gambar 7 yang terjadi pada kecepatan angin $6 \mathrm{~m} / \mathrm{s}$ lihat gambar 5 .

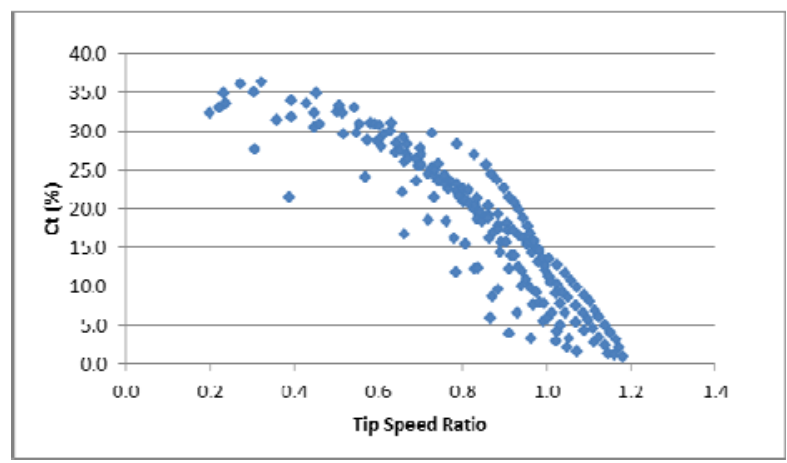

Gambar 8. Variasi Ct terhadap tip speed rasio untuk bilah dengan free drag reducing

Untuk karekteristik aerodinamis berupa sebaran koefisien torsi model uji turbin angin $(\mathrm{Ct})$ terhadap tip speed rasio $(\lambda)$ dipaparkan pada gambar 8 untuk penambahan bilah dengan free drag reducing dan gambar 9 untuk penambahan bilah dengan fix drag reducing.

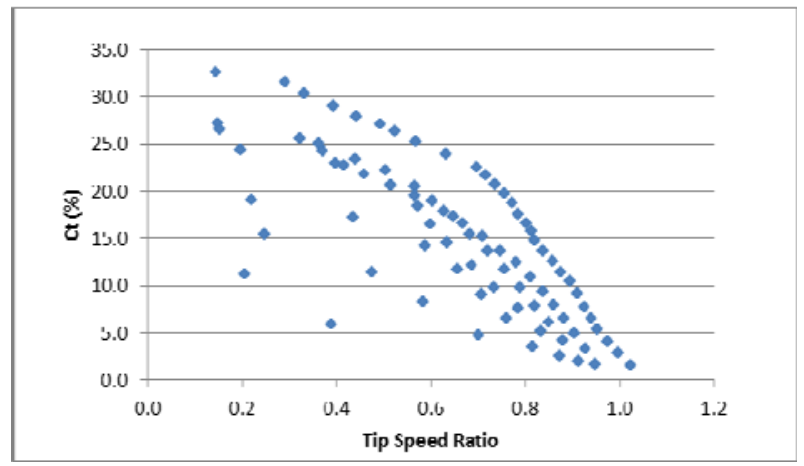

Gambar 9. Variasi Ct terhadap tip speed rasio untuk bilah dengan fix drag reducing 
Dari gambar 8 dan 9 terlihat penambahan bilah dengan free drag reducing lebih mampu meningkatkan self starting dari turbin savonius daripada penambahan bilah dengan fix drag reducing hal dapat dilihat dari nilai koefisien torsi yang dihasilkan pada tip speed ratio yang rendah berada dalam rentang $32-37 \%$ jauh lebih besar dari pada nilai koefisien torsi yang dihasilkan bilah dengan fix drag reducing ang nilainya dalam rentang $11-33 \%$.

\section{KESIMPULAN}

Penambahan free drag reducing pada bilah turbin angin savonius mampu menghasilkan kinerja yang lebih baik secara signifikan daripada penambahan bilah turbin angin savonius dengan fix drag reducing di semua kecepatan angin yang diujikan.

\section{UCAPAN TERIMA KASIH}

Penulis mengucapkan terima kasih pada kementrian riset dan teknologi yang membiayai penelitian ini melalui skim Penelitian Dasar Unggulan Perguruan Tinggi dan Universitas Negeri Surabaya yang mendukung moril dan administratip agar penelitian ini berjalan dengan baik.

\section{REFERENS}

[1] Modi VJ, Fernando MSUK. On the performance of the Savonius wind turbine. In: 7th Wind Energy Symposium. ASME; 1988.

[2] Akwa JV, Vielmo HA, Petry AP. A review on the performance of Savonius wind turbines. Renew Sustain Energy Rev 2012;16:3054-64

[3] Rahai HR, Hefazi H. Development of optimum design configuration and performance for vertikal axis wind turbine. Feasibility Analysis and Final EISG (Energy Innovation Small Grant program) Report. Technical report. California: Energy Commission; 2005.

[4] Benesh AH. The Benesh wind turbine. In: 11th Wind Energy Symposium. ASME; 1992.

[5] Kamoji MA, Kedare SB, Prabhu SV. Experimental investigations on single stage modified Savonius rotor. Appl Energy 2009;86:1064-73.

[6] Mohamed MH, Janiga G, Pap E, Th_evenin D. Optimal blade shape of a modified Savonius turbine using an obstacle shielding the returning blade. Energy Convers Manage 2011;52:236-42.

[7] Kacprzak K, Liskiewicz G, Sobczak K. Numerical investigation of conventional and modified Savonius wind turbines. Renew Energy 2013;60:578-85.

[8] Siregar. Indra Herlamba, Effendy. Moch, Rasyid. Akhmad Hafiz Ainur. Pengaruh Penambahan Fix Drag Reducing Pada Bilah Terhadap Kinerja Turbin Angin Savonius, Proc Seminar Nasional Tahunan Teknik Mesin 2018, hal 189-192.

[9] Wahid. Abdurrahma, Siregar Indra Herlamba, Study Experimental Turbin Angin Savonius 2 Tingkat dengan Penambahan Drag Reducing Pada Returning Blade (Studi Kasus Pada 2 Blade Pertingkat), Jurnal Pendidikan Teknik Mesin, 2018, Vol 7, No 1, Hal 78-82. 